\title{
Development of an experimental test rig for the pyrolysis of plastic residues and waste tires
}

\author{
Massimo Milani ${ }^{1}$, Luca $_{\text {Montorsi }}{ }^{1 *}$, Gabriele Storchi ${ }^{1}$, Matteo Venturelli ${ }^{1}$, Carlo Pirola ${ }^{2}$, Ermelinda Falletta $^{2}$, \\ ${ }^{1}$ Department of Sciences and Methods for Engineering - University of Modena and Reggio Emilia, Via Amendola 2, 42122 Reggio \\ Emilia, Italy \\ ${ }^{2}$ Department of Chemistry - University of Milan, Via Golgi, 19, 20133 Milan, Italy
}

\begin{abstract}
The paper presents the design of the experimental apparatus developed in order to analyse the performance of a prototype of a pyrolysis system for the exploitation of the plastic residues of industrial processes and the end of life tires. The small scale pilot prototype is specifically designed for carrying out an experimental campaign aimed at determining the influence of different plastic types on the yield and on the quality of the liquid oil, gas and char obtained in the pyrolysis process. The study investigates the effect of different mixture of various plastic products mainly made of polyethylene, styrene butadiene rubber, nylon and natural rubber. The prototype is equipped with a control system able to monitor the main operating parameters of the process, such as the pyrogas pressure and temperature as well as the temperature inside the reactor where the pyrolysis takes place. The monitored variables are employed for deriving correlations among the operating conditions and the yield of the pyrolysis process. Therefore, further analysis concerns experimental measurements in order to estimate the main compounds that are contained in the syngas in comparison to the different plastic wastes analysed. Finally, the emissions of the small-scale prototype are evaluated.
\end{abstract}

\section{Introduction}

The attention towards the efficient use of energy sources has increased substantially in the recent years due to the increasing awareness of the limits regarding the fossil fuels [1].

Thus, the scientific community and the Institutions are challenged in developing green energy systems capable to replace the fossil fuels.

Numerous technologies for producing bioenergy heat and power already exist, such as solid wood heating installations for buildings and biogas digesters for power generation as well as large-scale biomass gasification plants are also employed for heat and power generation $[2,3,4,5]$.

Within this context, plastics has attracted considerable interest since its production has reached about the 311 million tonnes in 2014 [6] determining a continuous growing in waste accumulation every year. Plastic solid waste (PSW) is being produced on a massive scale worldwide and its production crosses the 150 million tonnes per year globally, as presented in [7]. Due to its plentiful environmental impact, the plastic waste is becoming a key priority and different technologies for treating the plastic residues already exist.

Al Salem et al (2009) [8] presented a review on the different routes for recycling and recovery the plastic solid waste. They identified four different strategies for the PSW treatment such as re-extrusion, mechanical treatment, chemical treatment and energy recovery.

In 2017, Ragaert K. et al [9] presented a description of the main steps of the mechanical recycling which includes collection, sorting, washing and grinding of the material.

The amount of plastic disposed to landfill that is not treated via mechanical recycling can be used for energy recovery.

New sustainable processes of recycling have emerged, defined as chemical recycling [10], a process that convert plastic into liquids or gases which can be used as a fuel or as feedstock for the production of new plastic products [11]. Most of the studies available in literature present the gasification and the pyrolysis processes as the advanced thermal treatment methods for the reduction of the plastic waste.

Pyrolysis is the thermal decomposition process that occurs in the absence of oxygen and produces energy

\footnotetext{
*Corresponding author: luca.montorsi@unimore.it
} 
from waste in three different phases: solid bio-char, liquid oil and syngas [712].

In literature, many studies have been conducted regarding the influence of various types of plastics on the product yield. In [13] the set-up parameters are identified that affects the pyrolysis process and they include temperature, type of reactors, residence time, pressure.

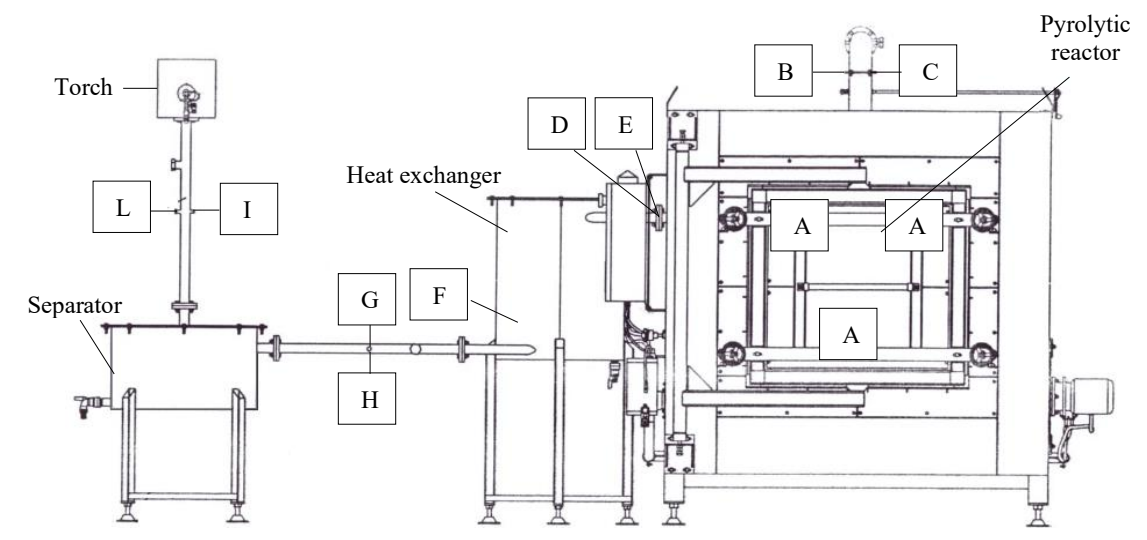

The pyrolysis process operates at high temperatures of $300-1000{ }^{\circ} \mathrm{C}[14,15,16]$.

In 2011, Kumar et al. [17] observed that the degradation of the polyethylene started at $400{ }^{\circ} \mathrm{C}$ and the maximum weight loss is at $427.7^{\circ} \mathrm{C}$.

Fig. 1. Schematic of the pilot plant and sensors location

In [18] the polystyrene pyrolysis was analyzed and the maximum yield of liquid oil was reached at $425{ }^{\circ} \mathrm{C}$. Kan et al [19] investigated the pyrolysis process of natural and synthetic rubber. The study determined the syngas composition by chromatographic techniques and demonstrated that the syngas is mainly composed by hydrogen and carbon monoxide; $\mathrm{H}_{2}$ was observed between 350 and $525^{\circ} \mathrm{C}$ for the natural rubber, while in the range $300-500^{\circ} \mathrm{C}$ hydrogen is the dominant species for the synthetic rubber.

In literature there are many studies that investigate different technologies and layout of the systems for the pyrolysis. One of these layouts is composed by a reactor, a distillation column, a condenser and a reboiler; the latter configuration consists of a reactor and a combustion chamber [12].

The aim of this paper is the design of a test rig for investigating the pyrolysis of different mixture of plastic waste. The experimental campaign focuses on the pyrolysis of polyethylene, styrene butadiene rubber, nylon and natural rubber. The experimental apparatus reproduces the layout presented in [12]. The prototype is composed by a pyrolysis reactor, heat exchanger, a separator and a filter. This configuration enables to produce energy from different plastic waste obtaining syngas, oil and solid bio-char [12].

The test rig is equipped with an acquisition system that monitors the main variables of the process by means of temperature and pressure sensors placed in characteristic position of the prototype. Therefore, it is possible to investigate the thermal behavior of the process and the influence of the operating temperature on the yield of the process.

Finally, by means of an industrial gas analyzer, tedlar gas sampling bag and SPME-GC/MS analyze the composition of the syngas and the main compounds generated by the syngas combustion in order to assess the sustainability of the process.

\section{Materials and methods}

This paper focuses on the development of a test rig for carrying out an experimental campaign to investigate the thermal behavior and the sustainability of the pyrolysis process of different plastic residues.

\subsection{Pilot plant}

\subsubsection{Layout}

Figure 1 depicts the structure of the pilot plant along with the main sensors used in the analysis. The experimental apparatus includes: a fixed reactor, a condenser/separator and a filter for the treatment of the exhaust generated by the syngas combustion.

The main unit is the reactor where the pyrolysis process takes place and it is composed by two detached cavities. The burner is placed in the external chamber and the air is maintained in circulation to transfer the heat uniformly to the internal cavity. The chemical transformation of the plastic waste occurs in the internal cavity which is completely sealed to avoid syngas leakages. The sealing action is performed by two different gaskets: the first made by silicone and the second one composed by an insulate fabric.

The internal cavity measures $1,5 \mathrm{~mm}$ thick and the internal volume is approximately $1 \mathrm{~m}^{3}$ that allows a material maximum load equal to $100 \mathrm{~kg}$.

A heat exchanger and a separator are connected downstream the reactor. The heat exchanger cools down the syngas to condensate the liquid part which is stored in the separator. The remaining syngas flows to the torch; in the real system the non-condensed syngas is used to power the reactor.

A scrubber system (not shown in Figure 1) is added before the exhaust chimney to filter the exhaust gases generated by the syngas combustion. 


\subsubsection{Monitoring System}

The sensors installed in the system are employed to monitor the main variables of the process.

The temperature distribution inside the internal chamber is monitored by three different thermocouples (A).

A temperature (D) and a pressure (E) sensor are installed to register syngas variables at the reactor outlet. The thermocouple $(\mathrm{F})$ measures the temperature of the water inside the heat exchanger. Furthermore, two thermocouples $(\mathrm{G}, \mathrm{I})$ and two pressure transducers $(\mathrm{H}$,
L) are positioned upstream and downstream the separator to monitor the temperature and pressure of the syngas respectively before and after its separation from the liquid phase.

Finally, a thermocouple (B) and a pressure transducer $(C)$ are placed at the chimney to measure the exhaust temperature and pressure generated by the GPL burner.

Table 1 lists the operating range and the accuracy of the measuring instruments employed to characterize the system.

Table 1. Specifications of the sensors installed

\begin{tabular}{|c|c|c|c|}
\hline Sensor type & Operating range & Accuracy & Reference letter in Figure 1 \\
\hline Thermocouples & $-270 \div 1370{ }^{\circ} \mathrm{C}$ & & $\mathrm{A}, \mathrm{B}, \mathrm{D}, \mathrm{F}, \mathrm{G}, \mathrm{I}$ \\
\hline Pressure sensor & $-1 \div 1 \mathrm{bar}$ & $<0.02 \% \mathrm{FS}$ & $\mathrm{E}$ \\
\hline Pressure sensors & $0 \div 0.5 \mathrm{bar}$ & $<0.02 \% \mathrm{FS}$ & $\mathrm{C}, \mathrm{H}, \mathrm{L}$ \\
\hline
\end{tabular}

Table 2. Experimental tests analysed

\begin{tabular}{|c|c|c|c|}
\hline Test & Typology & Main Compounds & Quantity [kg] \\
\hline$\# 1$ & Waste tyres & SBR & 34.5 \\
\hline$\# 2$ & Grocery bags & PE & 11.5 \\
\hline$\# 3$ & Fabrics and rubberized pipes & Nylon, SBR, NR & 21.7 \\
\hline
\end{tabular}

The data acquisition is carried out using a National Instrument DAQ module integrated by a customized LabView interface. Through this interface the user is also able to control remotely all the working parameters of the system.

\subsubsection{Industrial gas analyzer}

The composition of the syngas at the outlet of the separator is analyzed by means of an industrial gas analyzer.

The hardware technology is based on infrared sensors (NDIR) and electrochemical sensors (ECS) that enable the identification of the elements that compose the syngas.

The elements analyzed by the system are $\mathrm{O}_{2}, \mathrm{CO}$, $\mathrm{CO}_{2}, \mathrm{NO}, \mathrm{NO}_{2}, \mathrm{CH}_{4}, \mathrm{H}_{2}$ and they are measured as a percentage of the total mass.

\subsubsection{SPME-GC/MS analysis}

In order to obtain a more accurate analysis about the composition of the syngas produced during the experimental tests and the emissions of the small-scale prototype, different samples are collected during the whole duration of the experimental tests. Thanks to its waterproofing properties and not chemically interacting with gases inserted, Tedlar bags are used to guarantee the physical integrity of the collected samples which will therefore remain uncontaminated and unchanged without changes over time, even during storage.

The analyses of the collected samples are carried out by SPME-GC/MS technique.

\subsection{Experimental tests}

The collected plastic samples consist of waste tires, grocery bags, fabrics and vulcanized pipes that are mainly made of polyethylene, styrene butadiene rubber, natural rubber and nylon. The collected samples are used individually and as a mixture.
Table 2 lists the three experimental tests carried out in this study.

The pyrolysis process operates approximately between $400-420{ }^{\circ} \mathrm{C}$ and a retention time of 3-4 hours is used for all experiments depending on the composition of the materials of each batch cycle.

In the test rig, the chamber where the pyrolysis process takes place is directly connected with the external ambient: indeed, a hole on the backwall of the furnace enables the syngas to flow through the heat exchanger and the torch.

After the warmup phase of the system, the PSW starts transforming in syngas; as a consequence, the pressure inside the cavity increases and the syngas can gradually flow out from the cavity to the torch, where it is burnt and the exhaust are finally conveyed to the scrubber system.

\section{Results}

\subsection{Temperature and pressure analysis}

The experimental campaign explained in the previous paragraph is used for investigating the operating parameters in terms of temperature and pressure suitable for the pyrolysis process of the studied samples.

During the \#1 of the three scheduled tests the pyrolytic reactor is loaded with waste tires (4 SUV tires). The complete cycle lasted about $3 \mathrm{~h}$ and the transients related to the temperatures and pressures recorded by the sensors are presented below.

In Figure 2(a) the temperatures of the eight thermocouples installed are depicted.

The evolution of the temperature measured at the chimney explains the heating process of the pyrolytic cavity. Indeed, in the first part the temperature of the cavity is set approximately to $400{ }^{\circ} \mathrm{C}$ and remains constant for $15^{\prime}$ until a lower is defined and maintained constant until the end of the experimental test. 
Consequently, the temperatures measured by the three thermocouples installed into the internal chamber grow up to $400{ }^{\circ} \mathrm{C}$ and remain constant until the end. The curve named syngas input shows the temperature of the syngas at its exit from the internal cavity. This temperature remains lower than $100{ }^{\circ} \mathrm{C}$ and then gradually grows when the syngas starts to flow out.

The \#2 experimental test is conducted by introducing waste plastic bags into the inner cavity. During this test the input material was inserted into the pyrolytic reactor following a preheating of the cavity. In particular, the plastic bags are introduced inside the cavity once the same had been heated up to $100^{\circ} \mathrm{C}$.

The trend of the temperatures recorded during the test is shown in Figure 2(b).

Thanks to the temperature history represented in Figure 2(b), it is possible to reconstruct the entire development of the experimental test. For a period of time the pyrolytic reactor was kept at a constant temperature of about $350{ }^{\circ} \mathrm{C}$ which is then raised by a hundred degrees in order to allow the complete development of the process. In the final section you can see the first phase of shutdown and cooling of the pilot plant with the consequent reduction of all temperatures.
The \#3 experimental test is conducted by introducing vulcanized pipes and rubberized and metallic fabric into the inner cavity. The trend of the temperatures recorded during the test are represented in Figure 2(c).

After a first heating part of the pyrolytic reactor, the last one is kept at a constant temperature to facilitate the transformation of all the materials loaded. As can be seen from Figure 2(c), the increase in temperature measured at the syngas input coincides with the beginning of the formation phase of the syngas.

Figure 2(d) represents the trend of the pressures registered by the four pressure transducers during the $4 \mathrm{~h}$ duration of the \#2 experimental test and saved by the LabVIEW software. The trend of the pressures can be defined constant, following an initial settling phase. Indeed, the sensors, at the beginning of the test, register a pressure caused by the air remaining inside the system, which is driven by the hot vapors coming out of the pyrolytic reactor. Instead, in the conclusive part of the process when the pressure produced by the syngas is no longer significant, the pressures monitored inevitably drop.

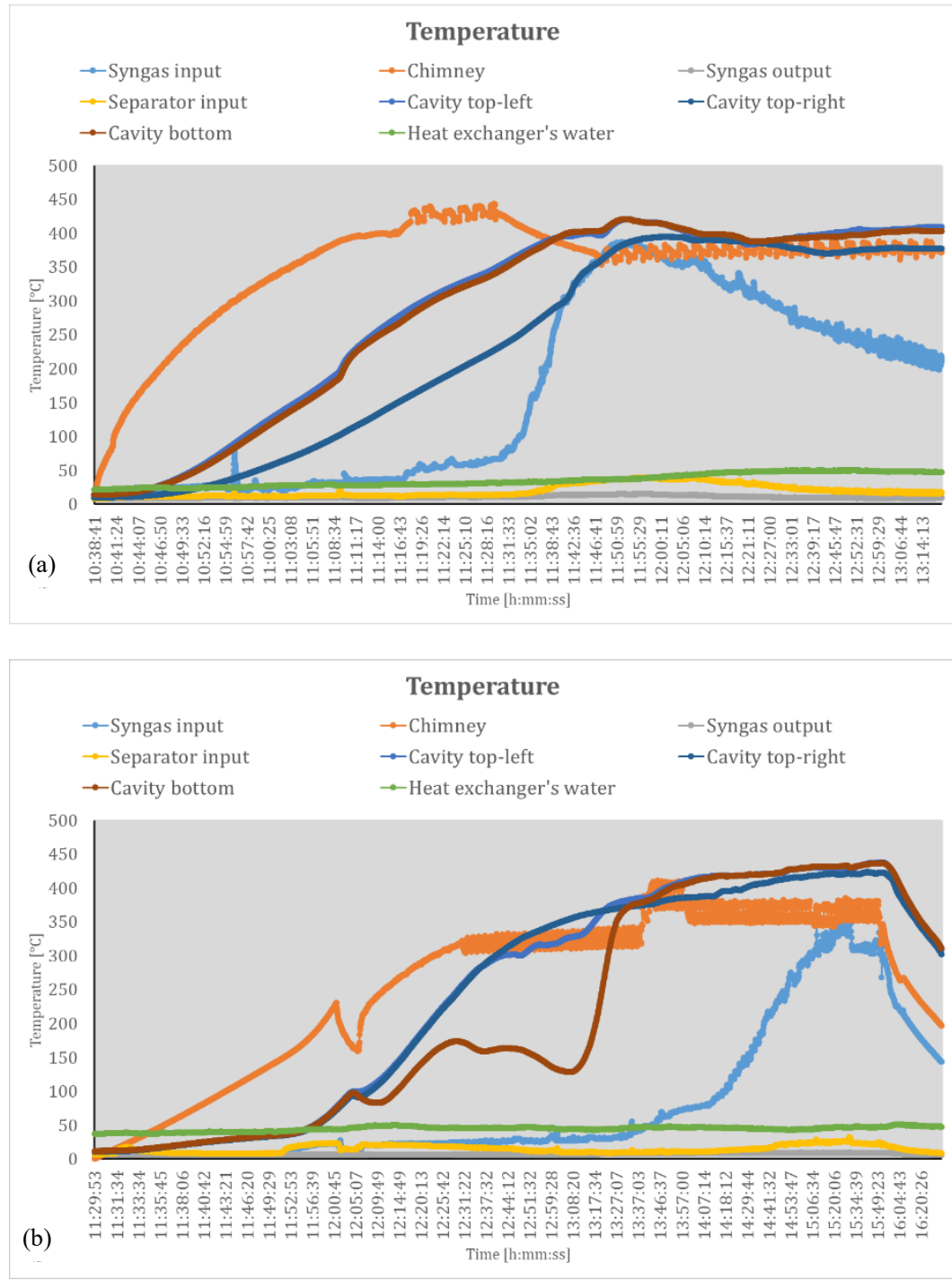



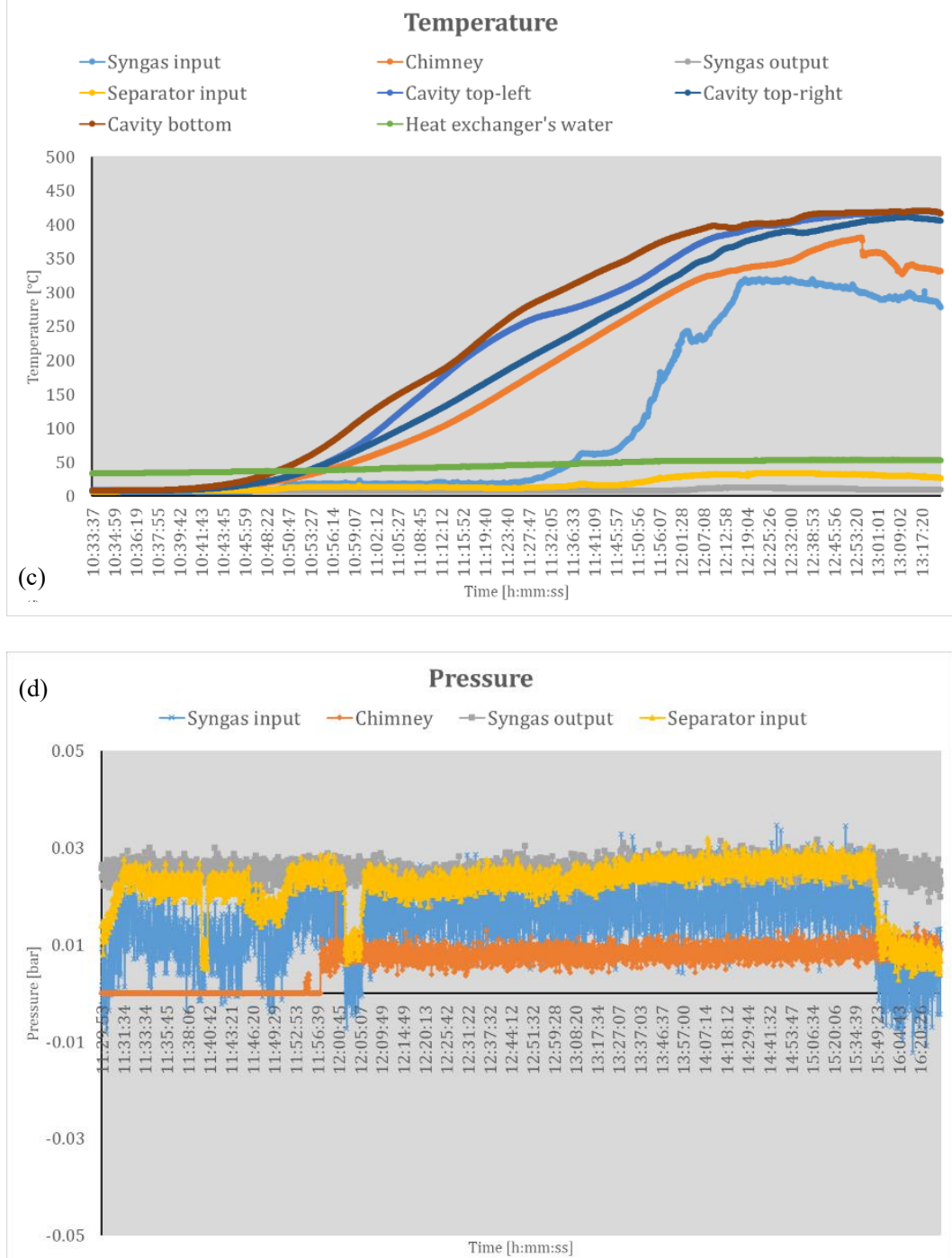

Fig. 2. (a) Waste tires pyrolysis temperatures graph, (b) Polyethylene bags pyrolysis temperatures graph, (c) Rubberized fabric and vulcanized pipes waste pyrolysis temperatures graph, (d) Polyethylene bags pyrolysis pressures graph

\subsection{Yields}

The effect of different plastic waste types on pyrolysis product yields is shown in Figure 3. All types of plastic waste are degraded at the pyrolysis temperature of 400 $420^{\circ} \mathrm{C}$.

At the end of the \#1 experimental test, as a result of the pyrolytic process, into the internal chamber of the reactor $16 \mathrm{~kg}(46 \% \mathrm{wt})$ of char and $5 \mathrm{~kg}(14 \% \mathrm{wt})$ of steel belts (used to reinforce SUV tires) remain on its bottom. From the separator $12 \mathrm{~kg}(36 \% \mathrm{wt})$ of raw fuel oil are collected (condensation temperature $=45^{\circ} \mathrm{C}$ ). Indeed, the pyrolysis of waste tires generally aims to maximize the yield of the liquid-phase product, because of the valuable chemicals obtained from it. By means of a simple subtraction it is possible to calculate exactly the amount of syngas generated by the pyrolytic process and burned by the torch: $1.5 \mathrm{~kg}(4 \% \mathrm{wt})$.

Thermal pyrolysis of grocery bags (PE) during the \#2 test produced relatively less amounts of liquid oil $(26 \%)$ and char (9\%) along with high yield of gases $(65 \%)$. Unlike the waste tires, which produce a significant amount of fuel oil, the polyethylene bags are transformed for most into syngas.
Results of the last (\#3) experimental test into the internal chamber can be resumed as: $4.5 \mathrm{~kg}(21 \% \mathrm{wt})$ of char and $3 \mathrm{~kg}(14 \% \mathrm{wt})$ of steel fibers (used to reinforce pipes and fabrics). Into the separator $9 \mathrm{~kg}(42 \% \mathrm{wt})$ of raw fuel oil are collected. Finally, the amount of syngas generated by the pyrolytic process and burned by the torch can be estimated into $5.2 \mathrm{~kg}(23 \% \mathrm{wt})$.

The average LPG consumption to power the furnace burner is approximately $7 \mathrm{~kg}$ per each experimental test.

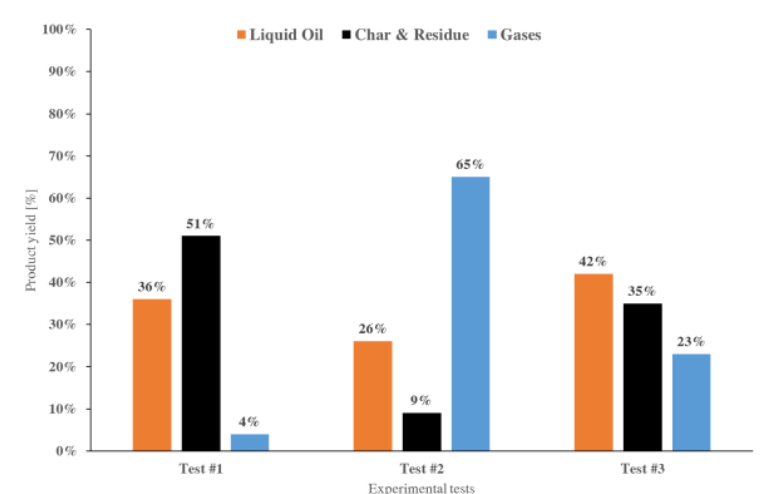

Fig. 3. Effect of plastic waste types on product yields 


\subsection{Composition}

Before considering the composition of the syngas in each experimental test, it is necessary to clarify that the volumetric composition presented into the three tables below is a mean value extracted from the measurements operated by the industrial analyzer.

Table 3. Volumetric syngas composition

\begin{tabular}{|c|c|c|c|c|c|c|c|}
\hline $\begin{array}{c}\text { Test } \\
\#\end{array}$ & $\mathbf{O}_{2}$ & $\mathbf{N}_{2}$ & $\mathbf{H}_{2}$ & $\mathbf{C O}$ & $\mathbf{C O}_{2}$ & $\mathbf{C H}_{4}$ & Total \\
\hline 1 & 1 & - & 48 & 10 & 19 & 22 & 100 \\
\hline 2 & 0.2 & 6 & 35.4 & 24 & 17.3 & 12.1 & 92 \\
\hline 3 & 1 & - & 25 & 9 & 28 & 32 & 95 \\
\hline
\end{tabular}

In Table 3 the composition of the syngas related to the three experimental tests is presented. Usually the gas-phase products from the pyrolysis of waste tires generally are paraffins (that were clearly visible on the bottom surface of the pipes), olefins, hydrogen, carbon oxides and other small number of other compounds. The $\mathrm{H}_{2}$ and $\mathrm{CH}_{4}$ occupied most of the volumetric composition unlike $\mathrm{CO}_{2}$ and $\mathrm{O}_{2}$ that represent either the $20 \%$ of the total volume of the syngas. Result of this particular volumetric composition the syngas extracted from waste tires has a high-calorific power.

Unlike the previous case related to the pyrolysis of waste tires, the volumetric composition of the pyrogas related to the \#2 experimental test varies slightly. Indeed, the percentages of $\mathrm{CH}_{4}$ and $\mathrm{H}_{2}$ are reduced as well as those related to $\mathrm{CO}$ and $\mathrm{CO}_{2}$ are increased. Moreover, the syngas relative to the pyrolysis of polyethylene bags is also characterized by minimum percentages of $\mathrm{N}_{2}$. Consequently, in this case the calorific value will be reduced compared to the previous one due to the different concentrations found. The remaining percentage points to get to $100 \%$ are relative to other components that the industrial analyzer is not able to determine.

Finally, the composition of the pyrogas obtained in \#3 shows that the $\mathrm{H}_{2}$ and $\mathrm{CH}_{4}$ occupied most of the volumetric composition and $\mathrm{CO}$ and $\mathrm{O}_{2}$ represent the $10 \%$ of the total volume of the syngas.

The analysis of the collected samples carried out by SPME-GC / MS technique are presented in the figure below. In this section, only the analyses related to the samples of syngas and exhaust fumes regarding the \#2 experimental test (PE bags). Indeed, this case turned out to be the most interesting concerning the quantity of gas that can be extracted from the plastic waste.

Figure 4 shows the chromatograms obtained for the two samples and a blank (the fiber after thermal cleaning).

As can be seen from the figure below, the two samples show chromatographic profiles very close to each other following an interesting trend between 13 and 20 minutes. Moreover, in the same interval of time, long chain heterocycles and esters have been mainly detected. The syngas sample shows the same chromatographic profile as the exhaust gases ones but a further characteristic peaks between 1 and $6.5 \mathrm{~min}$ can be also detected though less intense than the previous ones.

Table 4 shows the list of the analytes detected between 1-6.5 min identified by match with NIST 2014 library.

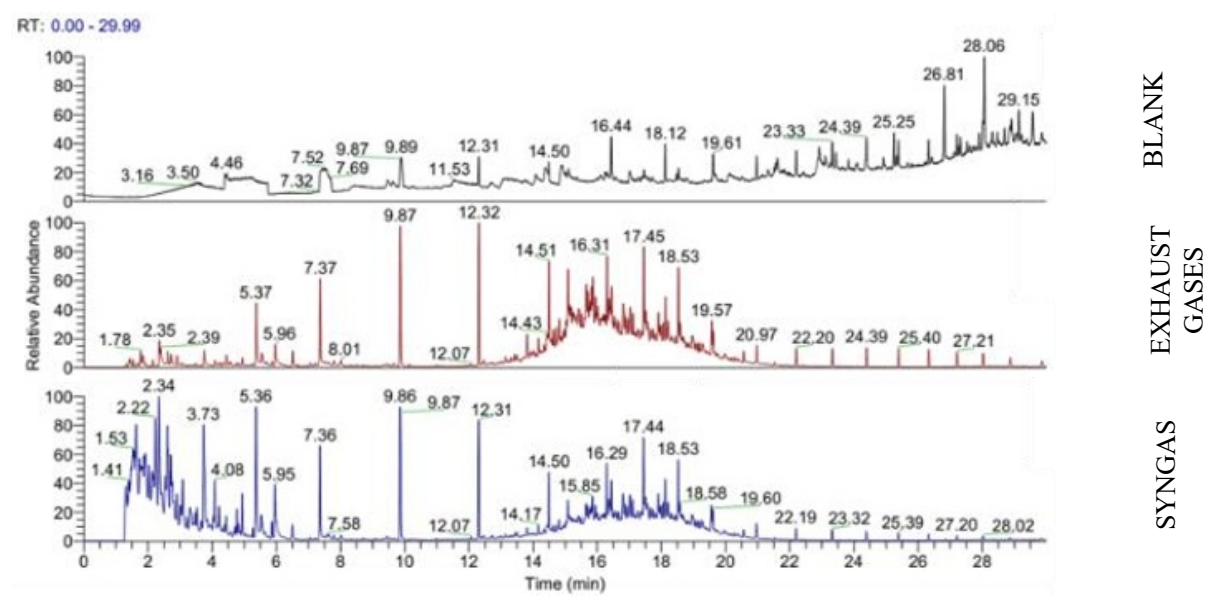

Fig. 4. Chromatograms of the blank and of the two analyzed samples.

Table 4. List of analytes in the 1-6.5 min interval.

\begin{tabular}{|c|c|c|}
\hline $\begin{array}{c}\text { RT } \\
\text { (min) }\end{array}$ & Match & Samples \\
\hline \multirow{2}{*}{1.31} & Methylenecyclopropane & EXHGAS, \\
& & GASES \\
\hline
\end{tabular}

\begin{tabular}{|c|c|c|}
\hline 1.33 & $\begin{array}{c}\text { Perfluorododecanoic } \\
\text { acid* }^{*}\end{array}$ & $\begin{array}{c}\text { SYNGAS, } \\
\text { EXHAUST } \\
\end{array}$ \\
\hline \multirow{2}{*}{1.41} & Gerfluorinated $*$ & SYNGAS, \\
& & EXHAUST \\
& & GASES \\
\hline
\end{tabular}




\begin{tabular}{|c|c|c|}
\hline 1.44 & $\begin{array}{l}\text { 3-hydroxy-2- } \\
\text { methylpentanale }\end{array}$ & $\begin{array}{c}\text { SYNGAS, } \\
\text { EXHAUST } \\
\text { GASES }\end{array}$ \\
\hline 1.54 & Perfluoro-1-heptene & $\begin{array}{c}\text { SYNGAS, } \\
\text { EXHAUST } \\
\text { GASES }\end{array}$ \\
\hline 1.77 & Hexene & $\begin{array}{c}\text { SYNGAS, } \\
\text { EXHAUST } \\
\text { GASES }\end{array}$ \\
\hline 1.77 & Perfluorinated* & $\begin{array}{c}\text { SYNGAS, } \\
\text { EXHAUST } \\
\text { GASES }\end{array}$ \\
\hline 1.81 & Pentane & $\begin{array}{c}\text { SYNGAS, } \\
\text { EXHAUST } \\
\text { GASES }\end{array}$ \\
\hline 1.85 & Perfluorinated* & $\begin{array}{c}\text { SYNGAS, } \\
\text { EXHAUST } \\
\text { GASES }\end{array}$ \\
\hline 1.90 & Perfluorinated* & $\begin{array}{c}\text { SYNGAS, } \\
\text { EXHAUST } \\
\text { GASES }\end{array}$ \\
\hline 2.14 & Perfluorinated* & $\begin{array}{c}\text { SYNGAS, } \\
\text { EXHAUST } \\
\text { GASES }\end{array}$ \\
\hline 2.34 & Benzene & $\begin{array}{c}\text { SYNGAS, } \\
\text { EXHAUST } \\
\text { GASES }\end{array}$ \\
\hline 2.39 & 3-methyl-4-penten-2-ol & $\begin{array}{c}\text { EXHAUST } \\
\text { GASES }\end{array}$ \\
\hline 2.63 & Heptene & $\begin{array}{c}\text { SYNGAS, } \\
\text { EXHAUST } \\
\text { GASES }\end{array}$ \\
\hline 2.72 & Perfluorinated* & $\begin{array}{c}\text { SYNGAS, } \\
\text { EXHAUST } \\
\text { GASES }\end{array}$ \\
\hline 2.91 & Perfluorinated* & $\begin{array}{c}\text { SYNGAS, } \\
\text { EXHAUST } \\
\text { GASES }\end{array}$ \\
\hline 3.03 & Perfluorinated* & $\begin{array}{c}\text { SYNGAS, } \\
\text { EXHAUST } \\
\text { GASES }\end{array}$ \\
\hline
\end{tabular}

\begin{tabular}{|c|c|c|}
\hline 3.09 & Cyclohexylmethane & $\begin{array}{c}\text { SYNGAS, } \\
\text { EXHAUST } \\
\text { GASES }\end{array}$ \\
\hline 3.47 & Perfluorinated* & $\begin{array}{c}\text { SYNGAS, } \\
\text { EXHAUST } \\
\text { GASES }\end{array}$ \\
\hline 3.73 & Toluene & $\begin{array}{c}\text { SYNGAS, } \\
\text { EXHAUST } \\
\text { GASES }\end{array}$ \\
\hline 4.09 & Octene & $\begin{array}{c}\text { SYNGAS, } \\
\text { EXHAUST } \\
\text { GASES }\end{array}$ \\
\hline 4.23 & Octane & $\begin{array}{c}\text { SYNGAS, } \\
\text { EXHAUST } \\
\text { GASES }\end{array}$ \\
\hline 4.54 & Perfluorinated* & $\begin{array}{c}\text { SYNGAS, } \\
\text { EXHAUST } \\
\text { GASES }\end{array}$ \\
\hline 4.59 & Dimethyl-heptane & $\begin{array}{c}\text { SYNGAS, } \\
\text { EXHAUST } \\
\text { GASES }\end{array}$ \\
\hline 4.77 & Trimethyl-hexene & $\begin{array}{c}\text { SYNGAS, } \\
\text { EXHAUST } \\
\text { GASES }\end{array}$ \\
\hline 4.94 & Dimethyl-heptene & $\begin{array}{c}\text { SYNGAS, } \\
\text { EXHAUST } \\
\text { GASES }\end{array}$ \\
\hline 5.26 & trimethylcyclohexane & $\begin{array}{c}\text { SYNGAS, } \\
\text { EXHAUST } \\
\text { GASES }\end{array}$ \\
\hline 5.36 & Ethyl-benzene & $\begin{array}{c}\text { SYNGAS, } \\
\text { EXHAUST } \\
\text { GASES }\end{array}$ \\
\hline 5.54 & Xylene & $\begin{array}{c}\text { SYNGAS, } \\
\text { EXHAUST } \\
\text { GASES }\end{array}$ \\
\hline 5.86 & Nonene & $\begin{array}{c}\text { SYNGAS, } \\
\text { EXHAUST } \\
\text { GASES }\end{array}$ \\
\hline
\end{tabular}




\begin{tabular}{|c|c|c|}
\hline \multirow{2}{*}{5.95} & Styrene & SYNGAS, \\
& & EXHAUST \\
& & GASES \\
\hline \multirow{2}{*}{6.51} & & SYNGAS, \\
& Cumene & EXHAUST \\
& & GASES \\
\hline
\end{tabular}

\section{Conclusions}

In this paper a fixed plastic pyrolytic reactor prototype has been developed and implemented. The experimental test rig includes the heat exchanger, gas / liquid separator, the torch, and the exhaust treatment system.

The experimental test rig is equipped with specific sensors for the real time acquisition of the main variables of the pyrolysis process: in particular, temperatures and pressures in the main area of the system are registered by means of the LABView interface software.

An experimental campaign has been conducted testing three different samples of PSW: Waste tyres, grocery bags an fabric an rubberized pipes.

The percentages of the output products were monitored and compared with those already present in literature and a good agreement between the two was found.

The percentages of each compound/element constituting the syngas were analyzed in real time thanks to the industrial analyzer and values in line with those found in literature were obtained.

Finally, the composition of the syngas and the exhaust gases for the \#2 test, i.e. grocery bags, was investigated by means of SPME-GC/MS technique.

\section{References}

1. Mercati, S., Milani, M., Montorsi, L., \& Paltrinieri, F. (2013). Optimization of the working cycle for a hydrogen production and power generation plant based on aluminum combustion with water. International journal of hydrogen energy, 38(18), 7209-7217.

2. Montorsi, L., Milani, M., and Venturelli, M., "Economic assessment of an integrated waste to energy system for an urban sewage treatment plant: A numerical approach." Energy 158 (2018): 105-110.

3. Yoshida H, Christensen TH, Scheutz C. Life cycle assessment of sewage sludge management: a review. Waste Manag Res 2013;31(11):1083-101.

4. Li H, Larsson E, Thorin E, Dahlquist E, Yu X. Feasibility study on combining anaerobic digestion and biomass gasification to increase the production of biomethane. Energy Convers Manag 2015; 100:212-9.

5. Milani, M., Montorsi, L., \& Stefani, M. (2014). An integrated approach to energy recovery from biomass and waste: Anaerobic digestiongasification-water treatment. Waste management \& research, 32(7), 614-625.

6. The new plastic economy "Rethinking the future of plastics" Ellen Mcarthur Foundation 2016

7. Singh N., Hui D., Singh R., Ahuja I.P.S., Feo L., Fraternali F., Recycling of plastic solid waste: A state of art review and future applications, Composites Part B 115, pp. 409422 (2017)

8. Al-Salem S.M., Lettieri P., Baeyens J., Recycling and recovery routes of plastic solid waste (PSW): A review, Waste Management 29, pp. 2625-2643 (2009)

9. Ragaert K., Delva L., Van Geem K., Mechanical and chemical recycling of solid plastic waste, Waste Management 69, pp. 2458 (2017)

10. Angyal A., Miskolczi N., Bartha L., Petrochemical feedstock by thermal cracking of plastic waste, Journal of Analytical and Applied Pyrolysis 79, pp. 409-414 (2007)

11. Baeyens J., Brems A., Dewil R., Recovery and recycling of post-consumer waste materials. Part 2. Target wastes (glass beverage bottles, plastics, scrap metal and steel cans, end-of-life tyres, batteries and household hazardous waste), International Journal of Sustainable Engineering 3, pp. 232-245 (2009)

12. Jouhara H., Ahmad D., Van den Boogaert I., Katsou E., Simons S., Spencer N., Pyrolysis of domestic based feedstock at temperatures up to $300{ }^{\circ} \mathrm{C}$, Thermal Science and Engineering Progress 5, pp. 117-143 (2018)

13. Anuar Sharuddin S.D., Faisal A., Wan Daud W.M.A., Aroua M.K., A review on pyrolysis of plastic wastes, Energy Conversion and Management 115, pp.308-326 (2016)

14. Ahmad I., Khan M.I., Khan H., Ishaq M., Tariq R., Gul K. et al, Pyrolysis study of polyethylene and polypropylene into premium oil products, International Journal of Green Energy 12, pp. 663-671 (2015)

15. Sarcher M., Khabir A., et al, Waste polyethylene terephthalate (PETE-1) conversion into liquid fuel, Journal of Fundamentals of Renewable Energy and Applications 1, (2011)

16. Williams P.T., Williams E.A., Interaction of plastic in solid in mixed plastics pyrolysis, Energy Fuels 13, pp.188-196 (1999)

17. Kumar S., Singh R.K., Recovery of hydrocarbon liquid from waste high density polyethylene by thermal pyrolysis, Brazilian Journal of Chemical Engineering 28, pp. 659667 (2011)

18. Onwudili J.A., Insura N., Williams P.T., Composition of products from the pyrolysis of polyethylene and polystyrene in a closed batch reactor: effects of temperature and residence time, Journal of Analytical and Applied Pyrolysis 86, pp. 293-303 (2009) 
19. Kan T., Strezov V, Evans T. Fuel production from pyrolysis of natural and synthetic rubbers, Fuel 191, pp. 403-410 (2017). 